\title{
Embedded Subscriber Identity Module eSIM
}

\author{
Torsten J. Gerpott · Sebastian May
}

Received: 15 December 2016/Accepted: 7 February 2017/Published online: 24 April 2017

(C) Springer Fachmedien Wiesbaden 2017

Keywords eSIM $\cdot$ Mobile telecommunication · Value configurations $\cdot \mathrm{M} 2 \mathrm{M}$ communication

\section{Overview of the eSIM Concept}

The embedded subscriber identity module (eSIM) is a "small trusted hardware component, which may be soldered into [..] devices [...], to run the secure network access application(s) [...] and enable the secure changing of subscription identity and other subscription data" (GSMA 2011, p. 4). The eSIM performs the same task as a traditional SIM, which is the identification and authentication of users seeking access to a mobile radio network. However, with the eSIM, a user's identification module is no longer personalized for a single application at the time of the card's manufacturing. Instead, the eSIM relies on a late personalization process, which is carried out remotely over the air when the access seeker calls up eSIM functions for the first time and subsequently (Oberender 2015). Thus, eSIMs enable users to (1) switch between multiple contracts and/or providers on a single appliance without having to exchange a hardware component and (2) employ multiple appliances with one contract without the need to

Accepted after one revision by Prof. Dr. Weinhardt.

Univ.-Prof. Dr. T. J. Gerpott ( $($ ) · Dipl.-Ök. S. May Lehrstuhl Unternehmens- und Technologieplanung, Mercator School of Management, Universität Duisburg-Essen, Lotharstr. 65, 47057 Duisburg, Germany

e-mail: Torsten.Gerpott@uni-due.de

Dipl.-Ök. S. May

e-mail: Sebastian.May@uni-due.de manage the integration of various SIM cards functioning independently.

There are three categories of eSIM use cases, namely (1) machine-to-machine (M2M), (2) machine-to-person (M2P), and (3) hybrid M2M plus M2P telecommunication. The M2M category comprises all applications which establish connections and exchange data automatically without any mandatory interaction with humans. Examples for M2M uses are car connections to a back-end system for vehicle tracking, remote machine maintenance, and connected house alarm systems. In contrast, in the M2P segment, radio network-based services involve deliberate human user interactions with an eSIM device, which enables its owner both to communicate with another person and to process information made available by technical systems (e.g., an Internet server). Smartphones are part of this segment as well as tablets, connected TV set-top boxes, health trackers, watches, or other electronic consumer equipment. In hybrid M2M plus M2P applications, a module in a technical system, whose primary purpose is not to enable interpersonal communication, connects automatically with other machines but at the same time allows humans to interact with the system either to directly retrieve information or to use telecommunication services. An example for a hybrid M2M plus M2P use case are cars, which connect automatically to back-end systems in an emergency event and additionally enable passengers to manually access telecommunication services.

eSIMs have several design advantages over traditional SIM cards. The eSIM consumes less space as well as energy, and works in harsh conditions (e.g., extreme temperatures, pressure, humidity) (Vesselkov et al. 2015). This makes it possible to manufacture smaller, more lightweight, and robust connected technical systems. Furthermore, use cases that require more than one identification 
module can be run with a single profile (e.g., several eSIMs in one car). This drastically simplifies the process when the profile(s) is (are) to be changed, because it does not require any exchange of one or even several physical components (Beecham Research 2014). Finally, with the eSIM, all components of a connected system can use a radio network independently without a hub which manages various links. Thus, eSIM enables connection options which are either too expensive or too complicated to be delivered with traditional SIM cards.

While the technical processes behind the remote personalization and authentication of eSIMs are already well defined (GSMA 2014), the strategic business implications for various groups of players are yet to be analyzed. Therefore, we take a look at potential roles of the key players in an eSIM environment. Furthermore, we discuss implications for underlying business models in mobile telecommunications and Internet-of-Things (IoT) markets, and future research perspectives.

\section{Players in an eSIM Environment}

Generally, the eSIM concept implies a change of control regarding the identification module of public mobile radio networks as compared to traditional SIM cards which are delivered to the customer by a mobile (virtual) network operator (M[V]NO). The module is no longer physically installed on a SIM card. Instead, it is initially provisioned over the air as an application file. Users are subsequently able to remotely install further profiles of other service providers. While multiple profiles can be stored on a single eSIM, only one profile is active at a time.

There are four potential groups of players in this technology setting (cf., Meukel et al. 2015; Vesselkov et al. 2015):

- The eSIM vendor, which builds a smart universal integrated circuit card (UICC) capable of storing several applications, one of which serves as a SIM (ETSI 2016).

- The original equipment manufacturer (OEM), which produces telecommunication devices or other "things" carrying and working with an eSIM (e.g., smartphone, car, home appliance).

- The M(V)NO, which runs the radio networks over which the authentication process is conducted and which may also serve as a reseller of (telecommunication) devices with an eSIM.

- The independent profile manager, which stores various network or user profiles and runs the over-the-air process of transferring profiles to the hardware furnished with an eSIM.
The eSIM architecture involves three major roles that are distributed between these four players, namely, the profile generation, the profile delivery, and the profile administration role (Beecham Research 2014, p. 13; Meukel et al. 2015, p. 4; Oberender 2015, p. 242).

The profile generation process does not differ from the traditional SIM card issuing process. The eSIM vendor creates profiles with authentication information issued by the respective $\mathrm{M}(\mathrm{V}) \mathrm{NO}(\mathrm{s})$. However, the information is digitally stored and downloaded after being requested rather than eternally engraved onto a physical SIM chip. As there is no need for an exchange of hardware components, the generation of profiles must not necessarily remain in the hands of the eSIM vendor and/or the M(V)NO.

The profile delivery process connects the profile generation service to the eSIM by encrypting profiles and sending it to the eSIM. It replaces the distribution of traditional SIM cards carrying hard-wired profile data. The roll-out of eSIM profiles requires the establishment of (secure) telecommunications links between networked "things" and profile providers.

This profile administration process is achieved with the help of a universal discovery (UD) server. It contains a list of all eSIM profiles available on the market and is a prerequisite for profile downloads to the "thing" equipped with an eSIM. The initial operational profile may either stem from a specific $\mathrm{M}(\mathrm{V}) \mathrm{NO}$ (i.e., it is pre-provisioned) or customers may be explicitly asked to select an $\mathrm{M}(\mathrm{V}) \mathrm{NO}$. Profile administration processes can also be run on a unified platform by providers which are independent from M(V)NOs (GSMA 2016).

\section{Implications for eSIM Business Models}

For both providers and customers of mobile communication hardware and connectivity as well as companies supplying other connected objects carrying an eSIM, the crucial business issue is the question of who will lead the operating model or, in other words, who will be the dominant player in an eSIM-centered market. The literature suggests that there are three potential value network configurations of eSIM-based remote end customer management (Costes et al. 2015; Singhal et al. 2015; Vesselkov et al. 2015): It may be (1) OEM-centered, (2) MNO-centered, or led by (3) an independent party that serves as a "man in the middle" and provides a market place for matching offerings of OEMs and MNOs.

In the first configuration, the OEM (e.g., Samsung, Volkswagen) has the full authority over the initial profile of the eSIM. Frequently, OEMs have no strong incentive to restrict their distribution to one $\mathrm{M}(\mathrm{V}) \mathrm{NO}$ because this would jeopardize the market reach of their products. 
Therefore, they will most probably equip their devices with an option to switch to any operator, for instance based on the specifications by the GSMA (2016). However, in cases in which an OEM has teamed up with an $\mathrm{M}(\mathrm{V}) \mathrm{NO}$ to develop and offer proprietary network-based services as an additional differentiator for its hardware, consumers may experience a limited freedom of tariff choice as the OEM is likely to restrict connectivity options to its allied M(V)NO. Today, OEMs in specific markets already integrate nonremovable conventional SIMs of a specific MNO in their products. An example is the installment of Vodafone SIM cards in cars manufactured by BMW. The advent of the eSIM improves the bargaining position of OEMs vis-à-vis the MNOs: despite a firmly mounted SIM, OEMs can now credibly threaten to quickly switch to another MNO if they disagree with conditions of supply of their current connectivity provider.

Large OEMs with significant IT resources (e.g., global car producers) have strong incentives to manage the eSIM profile delivery and administration processes on their own. In contrast, small OEMs selling a limited number of eSIMconnected machines (e.g., surveillance cameras, electric transformers) are expected to capitalize on $\mathrm{M}(\mathrm{V}) \mathrm{NO}$ or newly emerging independent service providers specializing in such offerings.

A current example for an OEM-centered operating model is the "Apple SIM". It is a proprietary eSIM solution by Apple, which allows users of the iPad to choose from a limited list of data tariffs without the need to retrieve a physical SIM card.

In the second case, the $\mathrm{M}(\mathrm{V}) \mathrm{NO}$ mainly sells $\mathrm{M} 2 \mathrm{P}$ telecommunication appliances along with a proprietary initial eSIM profile directly to consumers and business accounts. The device's preinstalled user profile presents the customer with a limited choice of tariffs by the issuing $\mathrm{M}(\mathrm{V}) \mathrm{NO}$. In an eSIM setting, $\mathrm{M}(\mathrm{V}) \mathrm{NO}$ are strongly incentivized to offer subsidized devices along with longterm contracts to erect barriers against customer churn resulting from the option to switch suppliers without having to exchange a SIM card. This makes it harder for equipment manufacturers without a direct "listing" by strong $\mathrm{M}(\mathrm{V}) \mathrm{NOs}$ to sell their hardware at unsubsidized prices covering their costs. Furthermore, M(V)NOs may refrain from minimizing the technical knowledge requirements for consumers to reprogram an eSIM to prevent that subscribers use the enhanced possibilities to move to a competitor. Hence, the situation in an $\mathrm{M}(\mathrm{V}) \mathrm{NO}$-centric market is similar to the current market with conventional SIM cards.

Although numerous telecommunication device producers have announced to release models with an eSIM, for the time being the current SIM card form is still prevalent. Thus, a transitioning phase is to be expected during which
$\mathrm{M}(\mathrm{V}) \mathrm{NOs}$ provide offerings already designed for eSIM capabilities while, at the same time, only a small share of all active devices has a built-in eSIM. For this phase, many eSIM vendors will provide their cards in the form of a traditional SIM, but will already make them reprogrammable. In this way, the new capabilities of the eSIM can be used in (older) devices, which were not initially equipped with a soldered eSIM, and device manufacturers are able to sell their products in both countries that do as well as in those that do not allow eSIM usage (Costes et al. 2015).

In the third case, an independent third party with strong eSIM design and/or mass data administration skills (e.g., Gemalto, Google) delivers the respective profiles. Upon the initial activation, customers can choose from all tariff options that are listed on the independent provider's platform or use a quick response code to download an $\mathrm{M}(\mathrm{V}) \mathrm{NO}$ 's profile they purchased in advance. From an end user perspective, this is an advantageous scenario as it provides a unified open platform that allows for a multitude of different $\mathrm{M}(\mathrm{V}) \mathrm{NO}$ service offerings while, at the same time, the choice of appliances is not limited (Costes et al. 2015; Meukel et al. 2015; Vesselkov et al. 2015).

The relative superiority of OEM, M(V)NO, and independent platform provider positioning efforts will determine in which of the three directions markets will evolve in the long run.

\section{Perspectives}

Despite its imminent market introduction, eSIMs feature several unresolved issues. First, it is unclear which of the current market players will invest to take a new role. Second, contrary to the popular notion that eSIM diffusion will ease supplier switching for consumers, it cannot be taken for granted that the competitive intensity in the mobile communication services market will increase automatically. As shown in Sect. 3, OEMs and M(V)NOs with strong market power still have the possibility to limit customer choices. This may induce the need to implement regulatory safeguards against anti-competitive strategies of both groups of players. Third, it is an open question whether the GSMA platform solution will succeed as the industry standard for the provision of eSIM user profiles.

From a consumer perspective, an unresolved key theme is the digital representation of individual profiles. Without a physical component consumers need a tool to administer their digital identity and the devices which are connected to it. Hence, IT researchers and practitioners should strive to put more emphasis on the development of secure and easyto-use consumer options to manage their digital eSIM profiles. 


\section{References}

Beecham Research (2014) Benefits analysis of GSMA embedded SIM specification on the mobile enabled M2M industry. London. http://www.gsma.com/newsroom/wp-content/uploads/BRL-Ben efits-Analysis-GSMA-Embedded-SIM-Specification-2014.pdf. Accessed 08 Feb 2017

Costes E, Perrin B, Chabrelle T, Melbouci L (2015) Embedded SIM study, update. Ernst \& Young, Paris. https://webforms.ey.com/ Publication/vwLUAssets/EY-mobile-network-operator/\%24FILE/ EY-Embedded-Sim-Studdy-White-Paper-September-2015.pdf. Accessed 08 Feb 2017

ETSI (2016) Smart Cards; UICC-Terminal interface; Physical and logical characteristics (Release 13), ETSI TS 102221 V13.1.0 (2016-05), Sophia Antipolis. http://www.etsi.org/deliver/etsi_ts/ 102200_102/102221/13.01.00_60/ts_102221v130100p.pdf. Accessed 08 Feb 2017

GSMA (2011) Embedded SIM task force: requirements \& use cases, Version 1.0, London. ftp://ftp.3gpp2.org/TSGS/Working/_2011/ 2011-0505-TSG-S+TSG-C_re_eUICC/Embedded $\% 20$ SIM $\% 20$ Use \%20Cases\%20and\%20Reqts\%20v1\%200.pdf. Accessed 08 Feb 2017

GSMA (2014) Embedded SIM remote provisioning architecture, Version 1.1, London. http://www.gsma.com/connectedliving/
wp-content/uploads/2014/01/1.-GSMA-Embedded-SIM-Remote-Pro visioning-Architecture-Version-1.1.pdf. Accessed 08 Feb 2017

GSMA (2016) RSP architecture, Version 2.0, London. http://www. gsma.com/rsp/wp-content/uploads/docs_new/SGP.21_v2.0Architecture.pdf. Accessed 08 Feb 2017

Meukel M, Schwarz M, Winter M (2015) E-SIM for consumers-a game changer in mobile telecommunications? McKinsey, Munich. https://www.mckinsey.de/files/mckinesey_e-sim_2.pdf. Accessed 08 Feb 2017

Oberender JO (2015) Embedded UICC. Datenschutz und Datensicherheit 10:240-245

Singhal P, Forst H, Ekström S, Sachdeva A, Costes E, Perrin B, Chabrielé T, Melbouci L, Djourabtchi G (2015) Mobile network operator on-demand subscription management study. Ernst \& Young, London. http://www.ey.com/Publication/vwLUAssets/ EY-mobile-network-operator-on-demand-subscription-manage ment/\$FILE/EY-mobile-network-operator-on-demand-subscrip tion-management.pdf. Accessed 08 Feb 2017

Vesselkov A, Hämmäinen H, Ikäläinen P (2015) Value networks of embedded SIM-based remote subscription management, in: 2015 Conference of Telecommunication, Media and Internet TechnoEcono-mics (CTTE), Munich. doi:10.1109/CTTE.2015. 7347220. http://ieeexplore.ieee.org/document/7347220/. Accessed 08 Feb 2017 